\title{
Rare Earth Elements and High Molecular Weight Oil Compounds
}

\author{
Tsoy K. S. ${ }^{1}$ \\ ${ }^{1}$ Federal State Autonomous Educational Institution of Higher Education, the Tomsk National Research State \\ University, Tomsk, Russia \\ Correspondence: Tsoy K. S., Federal State Autonomous Educational Institution of Higher Education, The Tomsk \\ National Research State University, 36, Lenina Av., Tomsk, 634050, Russia. E-mail: geohi70@yandex.ru
}

Received: September 20, 2014

Accepted: September 26, 2014

Online Published: December 29, 2014

doi:10.5539/mas.v9n1p211

URL: http://dx.doi.org/10.5539/mas.v9n1p211

\begin{abstract}
Herein, there has been reviewed the behavior of rare earth elements in oil, extracts of alcohol-benzene mixture of oil and gas formation deposit and high macromolecular weight oil compounds - lubricants, resins and asphaltenes of different regions. There have been shown the differences in the fractionation of REE compositions and differential behavior of individual lanthanides in REE composition of the high macromolecular weight compounds (HMWC) of the produced and residual oils. Spectra of lanthanide distribution in the REE composition of the initial oil and its HMWC selection from the exploration drilling wells compared with the similar REE distributions in the high molecular weight oil compounds from development drilling wells. There has been emphasized the difference in the distribution of individual lanthanides in REE composition as a consequence of redox conditions changes in the deposits during the oil and gas fields exploitation. Geochemical study shows uncharacteristic behavior of individual lanthanides associated with the possibility of finding praseodymium ( $\mathrm{Pr}$ ) and terbium $(\mathrm{Tb})$ in the tetravalent state, and the latter together with the neodymium $(\mathrm{Nd})$ participate in the isomorphism with the replacement of magnesium and calcium, and its subsequent accumulation in the high molecular weight oil compounds. The obtained results became rationale for the consideration of the behavior of rare earth elements in high molecular weight compounds of produced and residual oils in the form of creating process data sheet of the deposit and in perspective for the future establishment of correlational relationship in time between the lanthanide distributions in the REE composition of high molecular weight compounds during the exploitation of the field with quantitative yield of fluids.
\end{abstract}

Keywords: high molecular weight oil compounds, valence, isomorphism, redox conditions, petroleum fluids, normalization of the lanthanide concentrations, extracted and residual oils

\section{Introduction}

Considering the geochemistry of rare earth elements in the oil-and-gas bearing deposits in the applied direction and specifically for the purpose of its implementation in the practice of oil exploration works, we cannot ignore the behavior of lanthanide directly in oils themselves and in their fractions, especially in the high molecular weight compounds (HMWC) - lubricants, resins and asphaltenes. For this purpose, there were considered and determined the REE concentration in the oils selected from exploration and development drilling wells in various areas. This work was carried out in order to use the results of the oil industry researches, in consequence of the absence of reliable geochemical control methods during the field exploitation. There has been made an attempt to fill such gap on the REE behavior in the produced and residual oils in comparison with the exploration drilling oils up to the field exploitation. This comparison suggests fixation and differentiation in the behavior of individual lanthanides in composition of oil REE from the exploitation drilling wells, due to the forced change in the thermodynamic conditions in the deposit with the inflow of the additionally pumped stratum water and injection of the surface active substances (SAS) into the reservoir to increase the well debit. Hence, it is obvious that in the reservoir - collector, there take place dramatically sharp variations of the environment redox conditions, and certainly of the oil and gas hydrocarbon composition, as it has been recently discussed in the framework of the International Conference on "Oil and Gas Chemistry" (Institute of Petroleum Chemistry SB RAS, 24-28 September 2012, Tomsk). Thus, the chemical effect in conjunction with an increase in pressure in the reservoir should lead to a change in the composition of rare earth elements in the oil. However, according to the work (Gottikh et al, 1990), there has been found that the distribution of REE in oil is independent of hydrocarbon accumulation's localization depth, chemical quality of stratum waters, the underlying and 
surrounding deposits. Hence, the comparison of the two geochemical conditions and the establishment of differences in the lanthanide distribution of oil HMWC is the aim of the present work.

Targets of research. For this study there were selected produced and residual oils: of the Samotlor field (Russia, Western Siberia), "Karazhanbas" field (Kazakhstan), "Urshak" field (Bashkiria) and Ashalchinskoe deposit bitumen (Tatarstan), out of which there were extracted their high molecular weight compounds - resins, lubricants and asphaltenes, and defined concentration of rare earth elements. Also, there are provided the results of the analysis of REE contents directly in the oil taken from the South Pyzhinskaya 1 parametric well (Western Siberia), and in the high-molecular compounds of the alcohol-benzene mixture, after extracting rocks from the $12^{\text {th }}$ Kokdumalak oil and gas field well (Uzbekistan) taken from the earlier works and provided during the discussion process of this paper.

\section{Methodology of Thegeochemical Analysis}

Over the last years, for the normalization of data on rare earth elements, in order to reflect the geochemical processes through the construction of complete lanthanide spectra in the REE composition, most authors use the methods of normalization of rare earth elements to the North American shales (NASG) and are related to the research of rare earth elements in sediments on the analysis of the rock bank (Dubinin, 2006; Zanin et al., 2011; Gurari et al., 1984; Balashov, 1976). In this paper, for the interpretation of study results there was used the fractional approach to the rock analysis and normalization of bitumen REE and their fractions to chondrite carbonaceous (C1) (McDonough and Sun, 1995). This choice is dictated by us, in consequence of the contradictions between the absence of REE fractionation in sedimentary processes (Taylor and McLennan, 1988; Haskin et al, 1966; Balashov et al, 1966; Ronov et al., 1968) and the fact of detecting abnormal behaviors of individual lanthanides in rocks and their fractions of the oil and gas deposits (Balashov and Tsoy, 1989; Tsoy, 2013). In the first case, the reasons for the absence of fractionation follow from the Goldschmidt's assumption (Taylor and McLennan, 1988) as for the REE composition leveling in the sedimentary rocks due to the rock mixing in the magmatic and metamorphic processes and their subsequent juxtaposition on sedimentary processes over geological time (Taylor and McLennan, 1988, pp: 47-75). As a result, we have consistency in the nature of spectra of clarke REE composition distribution in sediment rocks, and, practically, absence of REE fractionation, not to mention the differential behavior of individual lanthanide in sedimentary processes. Absence of the REE fractionation, in general, in the sedimentary cycle is also emphasized in the work (Ronov et al., 1968). Hence, it follows that, according to the data of the content of rare earth elements of the rock bank, it is difficult to observe any significant fractionation of rare earth elements, in consequence of the homogenization of the sedimentary process compounds leading to clarke REE content in rocks and leveling the REE composition in these rocks, which became the reason for impossibility of detecting the REE fractionation. Therefore, the analysis of rare earth elements on the rock bank and subsequent normalization on NASG will not allow to identify the impact of oil and gas hydrocarbons on the REE fractionation in oil and gas-bearing deposits, and will only lead to the reflection and fixation of the total secondary (authigenic) mineralization due to the significant difference of weight concentrations of mineral and organic rock compounds. This can be observed by the nature of lanthanide distribution within the composition of the rock bank REE of the Krapivinskoe field (Western Siberia). Figure 1 shows that the nature of lanthanide distribution within the section samples of the oil-bearing deposit slightly differs from the nature of sedimentary rock REE distribution (Balashov, 1976). While the spectrum of acidic extraction lanthanides (Figures 2-3), in general, is enriched with the average REE with a significant depletion of light and heavy REE, with the absence of abnormal behaviors of individual lanthanides within the REE composition. From the standpoint of REE geochemistry, it may be only noted here the presence and the likelihood of a significant impact on the authigenic mineral formation on such lanthanide distribution in REE composition of the oil and gas-bearing deposits, which to some extent emphasizes their dissimilarity from the oil and gas non-productive sedimentary rocks. However, in practical terms, they do not carry the indicative information content and are considered to be a preliminary justification for the further researches on the subject of fractionation and monitoring differential behavior of individual lanthanides in REE composition of petroleum fluids.

1. As it can be seen from the Table 2, these are the contents of the oil and gas hydrocarbons of carbonate and reef deposits (the Kokdumalak oil and gas field) and high molecular weight oil compounds in the insoluble residue (IR) after the alcohol-benzene extraction, that are most similar in their compositions and lanthanide distributions in chondrites (C1). A fundamentally important issue here is to consider the impact factors on the REE fractionation in the sedimentary rocks: a) due to the possible inclusion of minerals rich in rare-earth elements into the clastic rock complex (from muscovite to feldspar and plagioclase) of the sediments (Taylor and McLennan, 1988, pp . 53), while, as it is now known (Balashov and Tsoy, 1989) the 
REE fractionating in oil and its fractions; b) solely due to the changes in the redox conditions of the environment, generated by the petroleum fluids themselves, as well as due to the possession of unique chemical properties of the individual lanthanides in the row $\mathrm{La}-\mathrm{Lu}$ and the ability to implement these fundamental properties within the conditions of immersion to a considerable depth of sediment rocks with the presence of organic matter and hydrocarbons of oil and gas. These properties are possessed by samarium, europium and ytterbium, which are able to revert within the hydrocarbon sharply restoring oil and gas environment to the divalent state with a change of the ionic radius $\left(\mathrm{Sm}^{2+}, \mathrm{Eu}^{2+}\right.$ and $\left.\mathrm{Yb}^{2+}\right)(\mathrm{Balashov}$ and Tsoy, 1989), as well as by cerium, praseodymium and terbium, which are also able to change themselves and be in the tetravalent state at the presence of petroleum fluids with changes made to the redox conditions of the environment for $\mathrm{Ce}^{4+}, \mathrm{Pr}^{4+}$ and $\mathrm{Tb}^{4+}$ (Tsoy, 2013). It is necessary to mention about the role of oil and gas hydrocarbons, such as stabilizers (screens) of the tetravalent state of the praseodymium and terbium (Tsoy, 2013). Therefore, the organic matter in sediments and hydrocarbons of oil and gas acquire a special status in the sedimentary processes and the nature of the distribution of rare earth elements in the oil and gas deposits will be determined, probably, to a large extent, by the thermodynamic conditions in the processes of oil formation and distribution. Moreover, as it is emphasized in the works (Balashov and Tsoy, 1989; Tsoy, 2013), the abnormal behaviors of individual lanthanides in the REE composition of organic complexes are weakly dependent on the geological and tectonic conditions of sedimentary deposits formation. Hence thereof, the approach to the interpretation of research results is obvious as a choice in favor of usage and through the normalization of the rare earth elements concentration in the samples of the rock organic complex (in the oil and its fractions, as well as in the samples of alcohol-benzene mixture (ABM) to the carbonaceous chondrites $(\mathrm{C} 1)$. In this paper, all the compositional variations of REE are given due to the normalization of lanthanide concentrations to the carbonaceous chondrites C1 (McDonough and Sun, 1995).

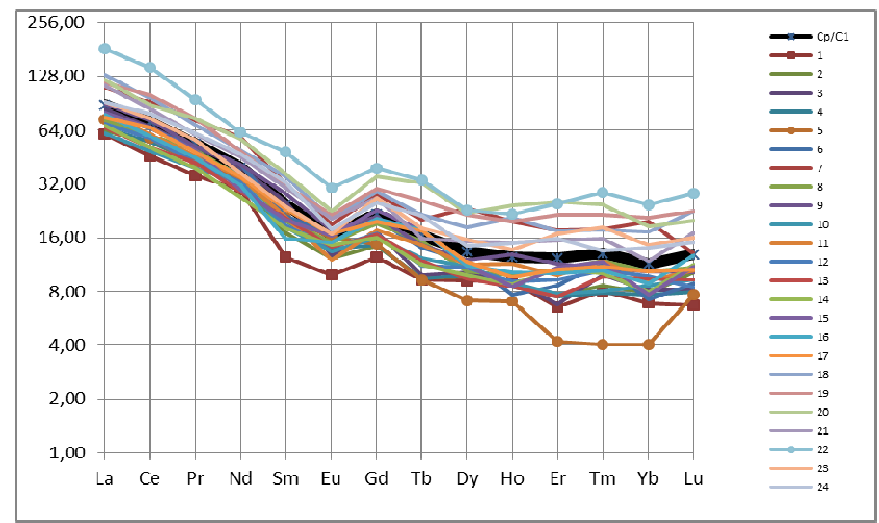

Figure 1. Compositional variations of REE in the section of the oil and gas deposit of the Krapivinskoe field after normalization of the composition of rock bank lanthanides to the carbonaceous chondrites $(\mathrm{C} 1)$

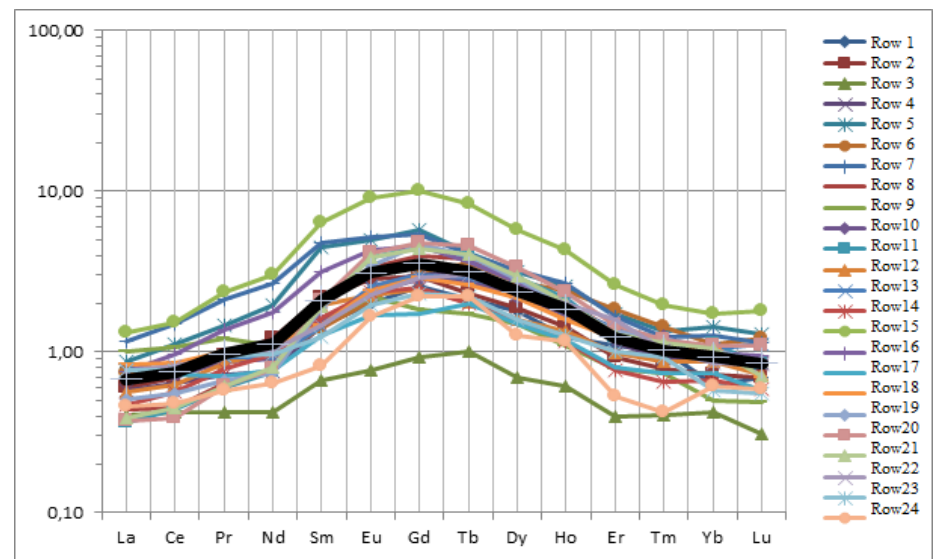

Figure 2. Compositional variations of REE in the section of oil and gas deposit of the Krapivinskoe field after normalization of lanthanide concentrations of the acid (1/8\% HCL) extraction to the North American shales (NASS). Row 25 is the average according to the deposit section 


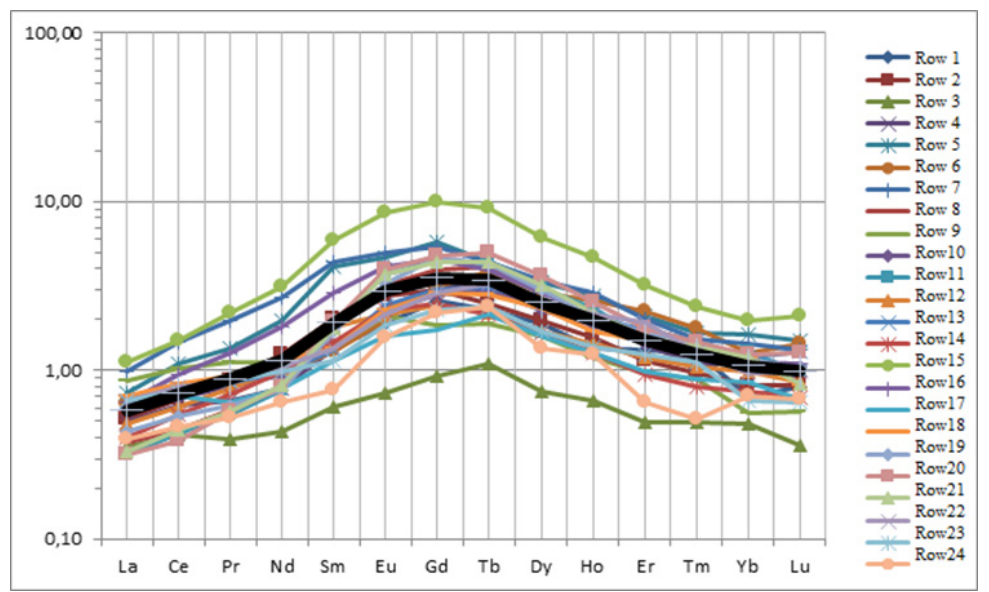

Figure 3. Compositional variations of REE in the section of oil and gas deposit of the Krapivinskoe field after normalization of lanthanide concentrations of the acid extraction $(1.8 \% \mathrm{HCL})$ to the clays of the Russian

Platform (RP). Row 25 is the average according to the deposit section

For identifying the causes of the anomalous behavior of individual lanthanides in oil and gas-bearing deposits, this approach is inadequate and ineffective, as it does not consider the presence of organic matter and the possible naphthides impact on the redox environment, and as a result, on the REE fractionation. This means that the REE analysis on the rock bank and mineral composition does not reveal to the full extant the processes of the REE fractionation in oil and gas-bearing deposits, which reduces the possibility of a more effective application of the results obtained from the geochemical studies of rare earth elements in the applied direction. Therefore, the fractional approach usage is the most consistent one for monitoring the lanthanide behavior differentiation in the movable mineral and organic complexes with regard to their balance to the rock bank.

1. Hence, in spite of the validity and appropriateness of the normalization of the research results to the North American shales (NASG) (Dubinin, 2006, pp: 24-26), we follow a different approach to the interpretation of the research results, as the processes of rare earth elements fractionation, considered in the oil and gas-bearing deposits, are held in other thermodynamic conditions, not comparable from the passage of surface geochemical processes recorded in the work (Dubinin, 2006). Further, the comparison of rare earth elements of the sedimentary, carbonate rocks and oil, presented in the Table 2 and taken from the work (Tsoy, 2013) and this work as well, has led us to the conclusion as for the appropriateness of the normalization of REE of the oil and its fraction samples to the carbonaceous chondrites (C1), with the current absence of average REE contents in oils. We should also not forget about the geochemical nature of the sedimentary rock formation, which differ from the formation of oil and gas hydrocarbons, in order to compare them for the purpose of observing the REE fractionation processes during the oil propagation just by means of the normalization to shales (Gromet et al, 1984) or clays (Migdisov et al, 1994).

Isolation of high molecular weight oil compounds and preparation for analysis on the content of trace elements were carried out at the Institute of Petroleum Chemistry SB RAS, Tomsk. Concentrations of rare earth elements in the HMWC of oils were determined through the ICP MS method and are presented in the Table 1.

\section{Results of the Hmwc Analysis}

Table 1. REE concentration in the high molecular weight compounds of oils from different regions, ppm

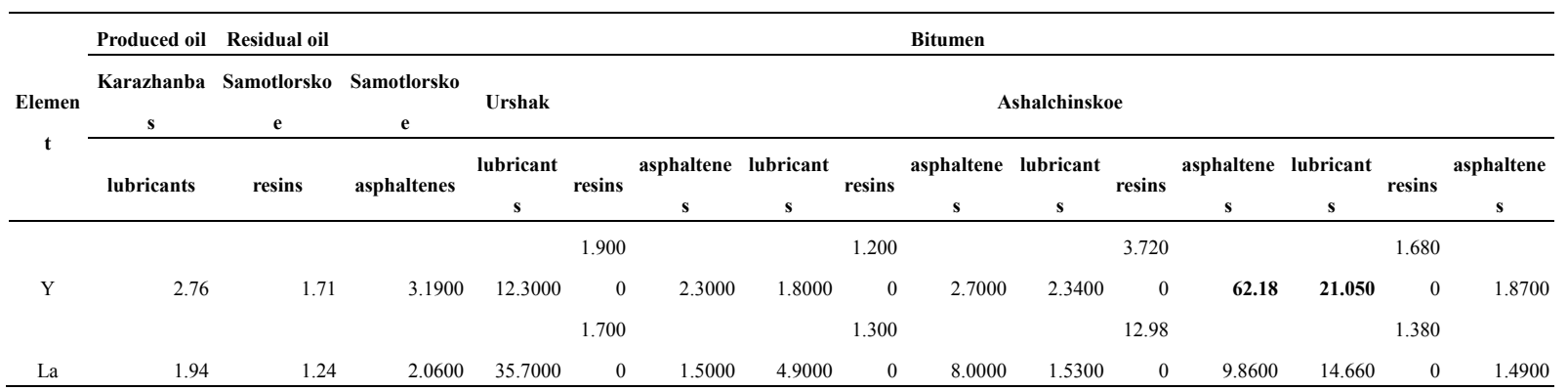




\begin{tabular}{|c|c|c|c|c|c|c|c|c|c|c|c|c|c|c|c|}
\hline \multirow[b]{2}{*}{$\mathrm{Ce}$} & \multirow[b]{2}{*}{3.68} & \multirow[b]{2}{*}{2.94} & \multirow[b]{2}{*}{3.4200} & \multicolumn{3}{|c|}{2.340} & \multicolumn{3}{|c|}{1.700} & \multicolumn{3}{|c|}{3.130} & \multicolumn{3}{|c|}{3.200} \\
\hline & & & & 2.8800 & 0 & 1.3400 & 2.2000 & 0 & 10.0000 & 3.0300 & 0 & 4.4500 & 31.660 & 0 & 3.7300 \\
\hline & & & & & & & & 280 & & & 10.81 & & & 0.310 & \\
\hline \multirow[t]{2}{*}{$\operatorname{Pr}$} & 0.44 & 0.28 & 0.4500 & 5.8700 & 0.420 & 0.4600 & 4.1000 & 0 & 3.0000 & 0.3600 & 0 & 3.4100 & 3.3500 & 0 & 0.3400 \\
\hline & & & & & 1.380 & & & 100 & & & 1.650 & & & 1.140 & \\
\hline \multirow[t]{2}{*}{$\mathrm{Nd}$} & 1.56 & 1.07 & 1.6200 & 1.7000 & 0 & 1.6800 & 1.6000 & 0 & 4.8000 & 1.2300 & 0 & 39.6100 & 11.730 & 0 & 1.2300 \\
\hline & & & & & 0.290 & & & 180 & & & 3.410 & & & 0.210 & \\
\hline \multirow[t]{2}{*}{$\mathrm{Sm}$} & 0.27 & 0.21 & 0.3100 & 1.9700 & 0 & 0.3800 & 1.3000 & 0 & 1.2000 & 0.2300 & 0 & 2.4500 & 2.1900 & 0 & 0.2400 \\
\hline & & & & & 0.078 & & & 044 & & & 0.190 & & & 0.069 & \\
\hline \multirow[t]{2}{*}{$\mathrm{Eu}$} & 0.078 & 0.15 & 0.0870 & 0.1480 & 0 & 0.0310 & 0.0980 & 0 & 0.1900 & 0.0700 & 0 & 0.4000 & 0.6800 & 0 & 0.0780 \\
\hline & & & & & 0.230 & & & 170 & & & 6.830 & & & 0.190 & \\
\hline \multirow[t]{2}{*}{$\mathrm{Gd}$} & 0.28 & 0.19 & 0.3200 & 3.0100 & 0 & 0.1500 & 1.5000 & 0 & 1.1000 & 0.2300 & 0 & 8.5400 & 2.1100 & 0 & 0.2300 \\
\hline & & & & & 0.043 & & & 039 & & & 5.570 & & & 0.033 & \\
\hline \multirow[t]{2}{*}{$\mathrm{Tb}$} & 0.067 & 0.027 & 0.0500 & 1.7520 & 0 & 0.0950 & 0.9700 & 0 & 1.4000 & 0.0400 & 0 & 15.3600 & 0.3900 & 0 & 0.0380 \\
\hline & & & & & 0.360 & & & 120 & & & 0.820 & & & 0.170 & \\
\hline \multirow[t]{2}{*}{ Dy } & 0.24 & 0.17 & 0.2500 & 0.6200 & 0 & 0.0600 & 0.3200 & 0 & 0.5700 & 0.1900 & 0 & 12.5300 & 1.9700 & 0 & 0.2100 \\
\hline & & & & & 0.083 & & & 034 & & & 7.890 & & & 0.035 & \\
\hline \multirow[t]{2}{*}{ Ho } & 0.059 & 0.031 & 0.0570 & 2.9700 & 0 & 0.0960 & 2.1000 & 0 & 0.9400 & 0.0450 & 0 & 3.4400 & 0.4100 & 0 & 0.0430 \\
\hline & & & & & 0.129 & & & 079 & & & 10.24 & & & & \\
\hline \multirow[t]{2}{*}{ Er } & 0.14 & 0.11 & 0.1400 & 4.1830 & 0 & 0.2750 & 2.8000 & 0 & 1.1000 & 0.1100 & 0 & 2.0400 & 1.1100 & 0.1100 & 0.1400 \\
\hline & & & & & 0.013 & & & 007 & & & 0.021 & & & 0.010 & \\
\hline \multirow[t]{2}{*}{$\mathrm{Tm}$} & 0.01 & 0.01 & 0.0140 & 0.0190 & 0 & 0.0034 & 0.0130 & 0 & 0.0320 & 0.0100 & 0 & 0.0610 & 0.1000 & 0 & 0.0120 \\
\hline & & & & & 0.045 & & & 025 & & & 0.120 & & & 0.026 & \\
\hline \multirow[t]{2}{*}{$\mathrm{Yb}$} & 0.038 & 0.027 & 0.0440 & 0.1480 & 0 & 0.086 & 0.0640 & 0 & 0.1600 & 0.0330 & 0 & 0.5300 & 0.3600 & 0 & 0.0430 \\
\hline & & & & & 0.003 & & & 003 & & & 0.032 & & & 0.003 & \\
\hline $\mathrm{Lu}$ & 0.0036 & 0.0024 & 0.0056 & 0.0190 & 0 & 0.0090 & 0.0130 & 0 & 0.0300 & 0.0030 & 0 & 0.1100 & 0.0290 & 5 & 0.0051 \\
\hline TR & 8.81 & 6.46 & 8.83 & 60.99 & 7.11 & 6.17 & 21.98 & .08 & 32.52 & 7.11 & 63.69 & 102.79 & 70.75 & 6.89 & 7.83 \\
\hline
\end{tabular}

TR - the sum of all lanthanides and yttrium. High molecular weight compounds in the oils were isolated and prepared for the trace element analysis in the Institute of Petroleum Chemistry SB RAS, Tomsk (analyst Gerasimova, N.N.). REE concentrations were determined by the ISP MS method in a certified laboratory of "Plasma", LLC, Tomsk (executor - Fedyunina, N.V.).

Table 2. Comparative table on the lanthanide distribution within various objects, ppm

\begin{tabular}{|c|c|c|c|c|c|c|c|c|c|c|c|c|c|c|c|}
\hline & $\mathbf{L a}$ & $\mathrm{Ce}$ & Pr & Nd & Sm & Eu & Gd & $\mathbf{T b}$ & Dy & Но & Er & $\mathbf{T m}$ & $\mathbf{Y b}$ & $\mathbf{L u}$ & Source \\
\hline NASC & 32 & 73 & 7.9 & 33 & 5.7 & 1.24 & & 0.85 & & 1.04 & 3.4 & 0.5 & & 0.48 & (Haskin, et al., 1966). \\
\hline $\mathbf{R P}$ & 37.5 & 74.8 & 8.6 & 32.2 & & 1.3 & 5.21 & 0.79 & 4.88 & 0.96 & 2.78 & 0.41 & 2.73 & 0.41 & (Balashov, et al., 1964). \\
\hline $\mathrm{C} 1$ & 0.237 & 0.613 & 0.093 & 0.457 & 0.148 & 0.056 & 0.199 & 0.0361 & 0.246 & 0.0546 & 0.16 & 0.0247 & 0.161 & 0.0246 & (Zanin, et al, 2011). \\
\hline HO & 1.5 & 0.66 & 0.22 & 0.74 & 0.14 & 0.028 & 0.17 & 0.027 & 0.22 & 0.079 & 0.137 & 0.018 & 0.09 & 0.017 & $\begin{array}{c}\text { (Taylor and McLennan, } \\
\text { 1988). }\end{array}$ \\
\hline Lubricants & s 1.94 & 3.68 & 0.44 & 1.56 & 0.27 & 0.078 & 0.28 & 0.067 & 0.24 & 0.59 & 0.14 & 0.01 & 0.038 & 0.0036 & Present work \\
\hline Lubricants & s 1.53 & 3.03 & 0.36 & 1.23 & 0.23 & 0.07 & 0.23 & 0.04 & 0.19 & 0.045 & 0.11 & 0.01 & 0.033 & 0.003 & Present work \\
\hline
\end{tabular}

Lubricants made from the oils of the "Karazhanbas" and "Urshak" fields are given from the Table 1.

\section{Discussion of the Results}

Let us consider the lanthanide distribution in the REE composition and compositional variations of REE in the oils and high molecular weight compounds, commonly observed in the spectra of initial oil sampling from the exploration drilling wells up to the industrial deposit exploitation (see Figure 4). 


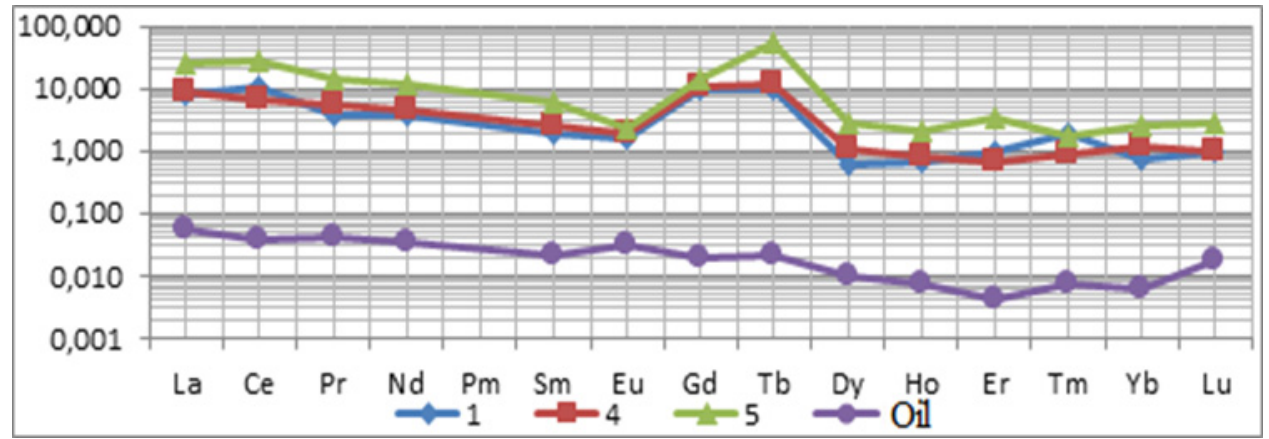

Figure 4. Distribution of lanthanides in the REE composition of the oils and extracts of alcohol-benzene mixture (form. 1, 4 and 5) of the rocks from the South Pyzhinskaya 1 (Western Siberia) parametric well, where 1 is from the Bazhenov Formation rocks, 4 - from the mudstone deposits, zones of oil and gas hydrocarbon generation, and 5 - from the carrier bed zone

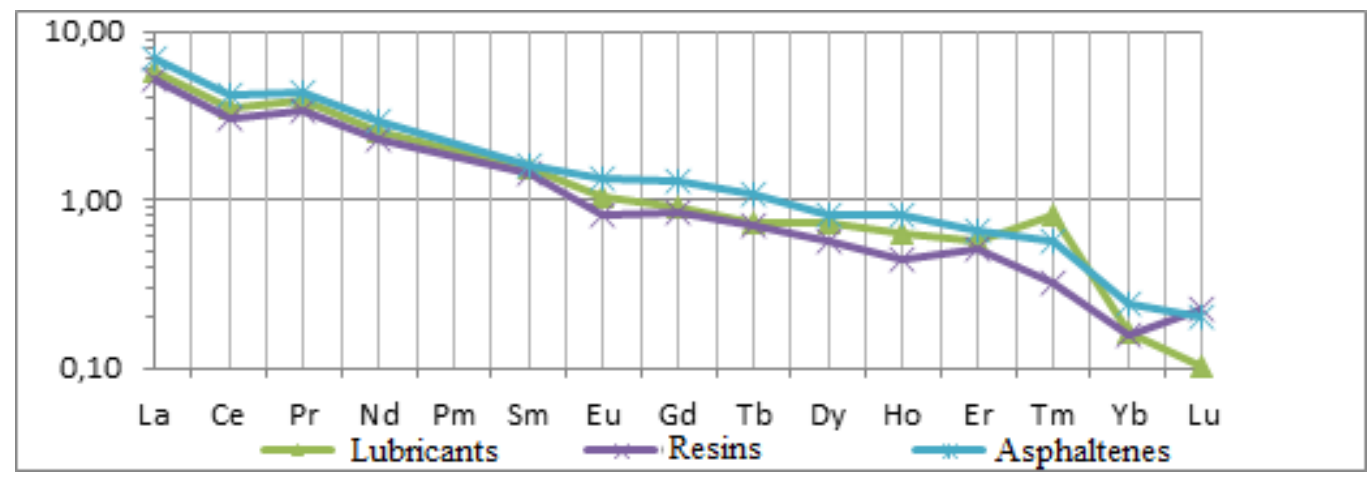

Figure 5. Distribution of lanthanide in the REE composition of the high molecular weight oil compounds of the Kok-Dumalak oil and gas-bearing field (Uzbekistan (Taylor and McLennan, 1988)

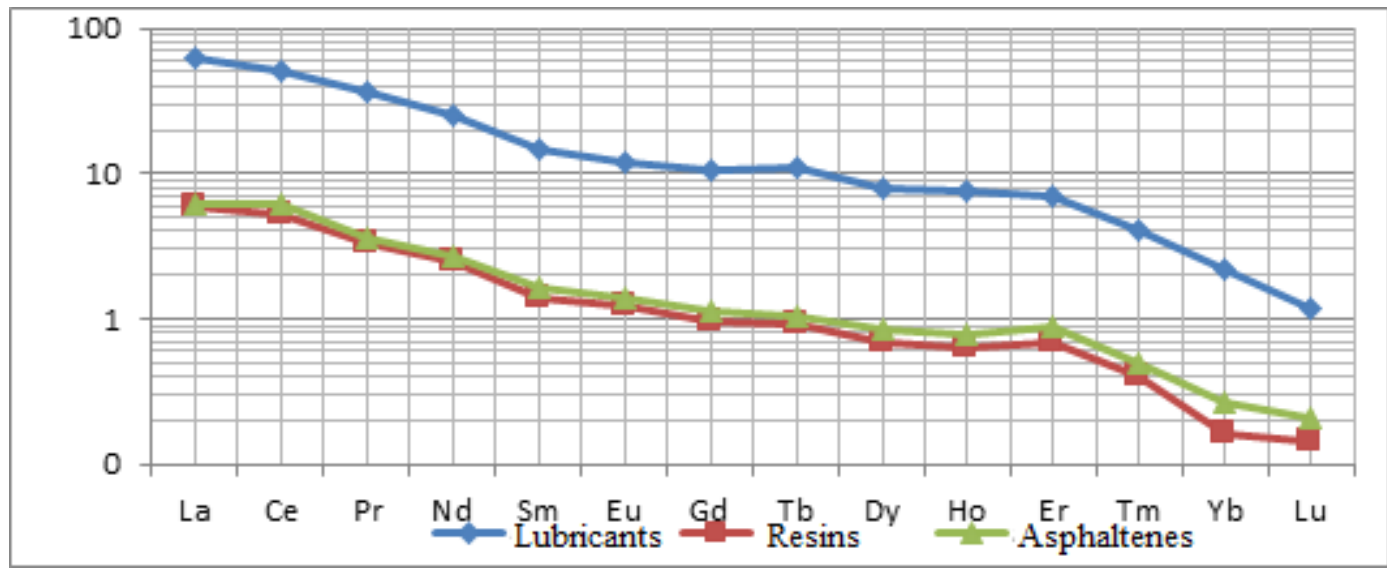

Figure 6. Distribution of REE compositions in the high molecular weight compounds of bitumen of the Ashalchinskoe field (Tatarstan)

As it can be seen from the Figure 2, the nature of the lanthanide distribution in the REE composition of is not distinguished by any significant fractionation between the lanthanides in the row $\mathrm{La}-\mathrm{Lu}$ ). This is also common for the oil's HMWC of the Kokdumalak oil and gas-bearing field (Figure 5). The difference is observed only in the REE concentration of lubricants from the REE concentration of resins and asphaltenes of the Ashalchinskoe field bitumen, due to the absence of emigration processes within the reservoir (Figure 6), without fixing any significant lanthanide fractionation in the REE composition in all oil's HMWC. In general, it can be stated that during the study of REE directly in the oils, the HMWC from oil and the HMWC from extracts of 
alcohol-benzene mixture do not demonstrate any sharply differentiated behavior of individual lanthanides, especially of those lanthanides that are capable of altering the valence states and ionic radii, due to the integrated method petroleum fluids sampling.

Geochemical situation changes dramatically when the studies on produced and residual oils, selected during the deposit development, are conducted (Figure 7, 9).

\section{Lubricants}

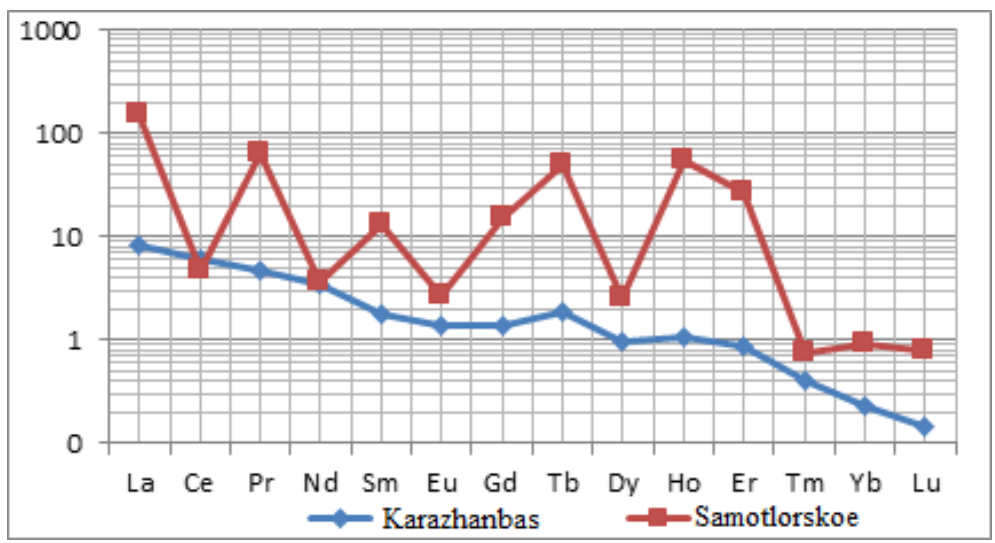

Resins

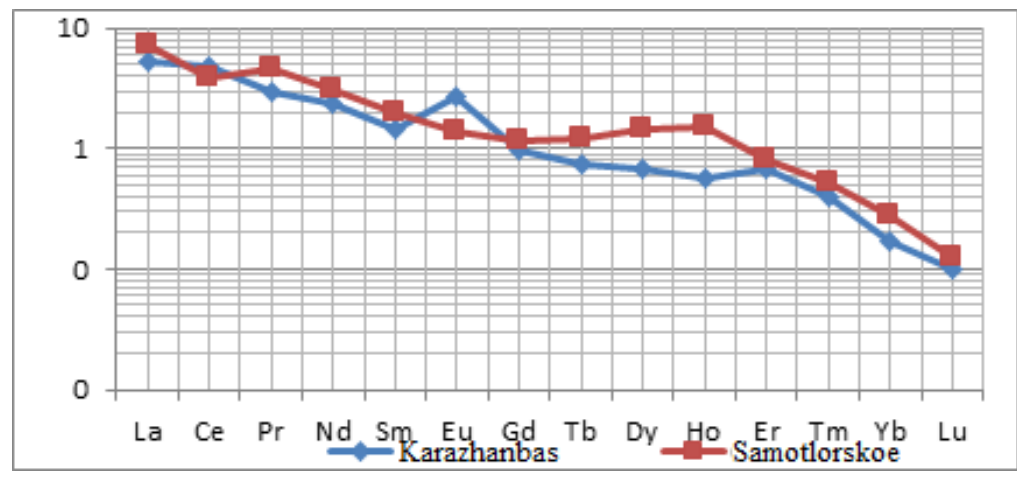

Asphaltenes

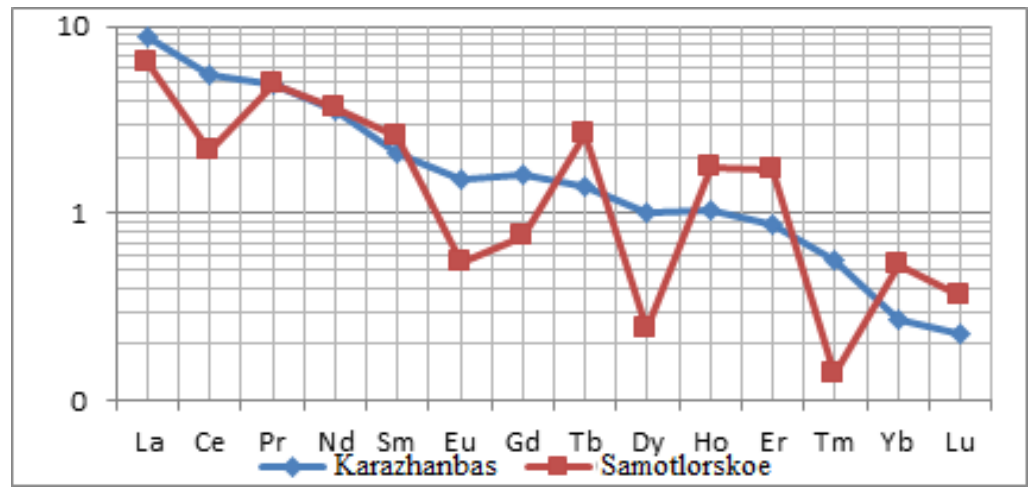

Figure 7. The contrast in the lanthanide distribution in the REE composition and their variations in the oil's HMWC (produced oil)

1. REE in the HMWC fractions of the produced oil. Comparison of the REE spectra in the HMWC of two fields shows that the REE in the fractions of "Karazhanbas" oil possess weak fractionation and are almost leveled in the spectrum of lanthanides in the REE composition and even have a positive anomaly on europium $(\mathrm{Eu})$ in there REE spectrum in the resins' HMWC that characterizes a weak impact of injected water and surface - active agents on the field development site. Quite different is the lanthanide distribution 
in the REE composition of the oils' HMWC is observed by us in the Samotlor field site. Abrupt changes in the lanthanide distribution in lubricants at first glance are similar to the lanthanide distribution without normalization and are close to the distribution of their regularities in accordance with the Oddo - Harkins rule (Dubinin, 2006). However, such lanthanides as praseodymium, terbium, and holmium ( $\mathrm{Pr}, \mathrm{Tb}$ and $\mathrm{Ho}$ ) do not comply with the rule of odd and even lanthanide accumulation, suggesting other causes of these anomalies in the spectrum of full REE composition. Most likely, the appearance of anomalies in the REE spectrum is conditioned upon their removal from the deposit site together with petroleum fluids and SAS. This may be connected only with movable components of oil and gas hydrocarbons (for example: with molecular dispersion of lubricants). Accumulation of lanthanides in lubricants and resins may be explained by the penetration of $\mathrm{Pr}$ and $\mathrm{Tb}$ in tetravalent forms into the organic phase rocks, which is probably due to the change of redox conditions of the environment and, undoubtedly, with higher migratory abilities (mobility) of lubricants and resins with respect to asphaltenes (asphaltenes, unlike lubricants and resins, are solids and could hardly move in a complex pore system of the oil bearing formation - reservoir (Tisso and Welte, 1981)). Consequently, it may be asserted that they (asphaltenes) cannot contribute to the migration processes of lanthanides and simultaneously serve as stabilizers for $\mathrm{Pr}^{4+}$ and $\mathrm{Tb}^{4+}$ (Tsoy, K.S., 2013), and be the causes of their unusual accumulation and anomalies in the spectrum of lubricants' REE distribution (lubricants, Figure 7). Most likely, the appearance of anomalies in the REE spectrum is conditioned upon their removal from the deposit site together with formation water and SAS together with the molecular solutions of lubricants. Accumulation of lanthanides in lubricants is explained by the penetration of $\mathrm{Pr}$ and $\mathrm{Tb}$ in tetravalent forms into the molecular solutions of the lubricants themselves due to their higher mobility in comparison with the resins and asphaltenes (asphaltenes are solids and could hardly move in a complex pore system (Tisso and Welte, 1981) and could serve as stabilizers for both $\operatorname{Pr}^{4+}$ and $\mathrm{Tb}^{4+}$ (Tsoy, 2013). Ho accumulation, caused by its participation in geochemical processes only in a trivalent state, suggests the possibility of its accumulation in the lubricants due to its removal from the zones of its isomorphism passage with yttrium (Tsoy, 2013) that in the future should be reflected in the lanthanide spectrum of the asphaltenes' REE composition, if our assumptions are correct. Indeed, as it can be seen from the Figure 7, in the spectrum of lanthanide distribution in asphaltenes, there are observed higher concentrations of Pr, Tb and Ho, which are not typical of other oil's HMWC. At the same time, there is observed an increased change in the concentration of neodymium $(\mathrm{Nd})$, which emphasizes its participation in the isomorphism with the replacement of magnesium $(\mathrm{Mg})$, similar to terbium with replacement of calcium $(\mathrm{Ca})$ in the hydrogen carbonates formed in the areas of oil-bearing deposits. Participation of calcium and magnesium in geochemical processes is justified by their precipitation as a result of solvation by organic acids of the oil and gas hydrocarbons (Tisso and Welte, 1981, p. 260-263) and the subsequent involvement of these elements with the lanthanides ( $\mathrm{Nd}$ and $\mathrm{Tb}$ ) into the isomorphism process (Tsoy, 2013). Reflection of these processes are observed in the lanthanide distribution in the REE composition of the Samotlor field resins in the Figure 7. And even more convincing are the theses on lanthanide isomorphism by comparing the spectra of lanthanide distribution of the carbonate reef sediments of the Kok-Dumalak oil and gas-bearing field and of the present work (see Figure 8).

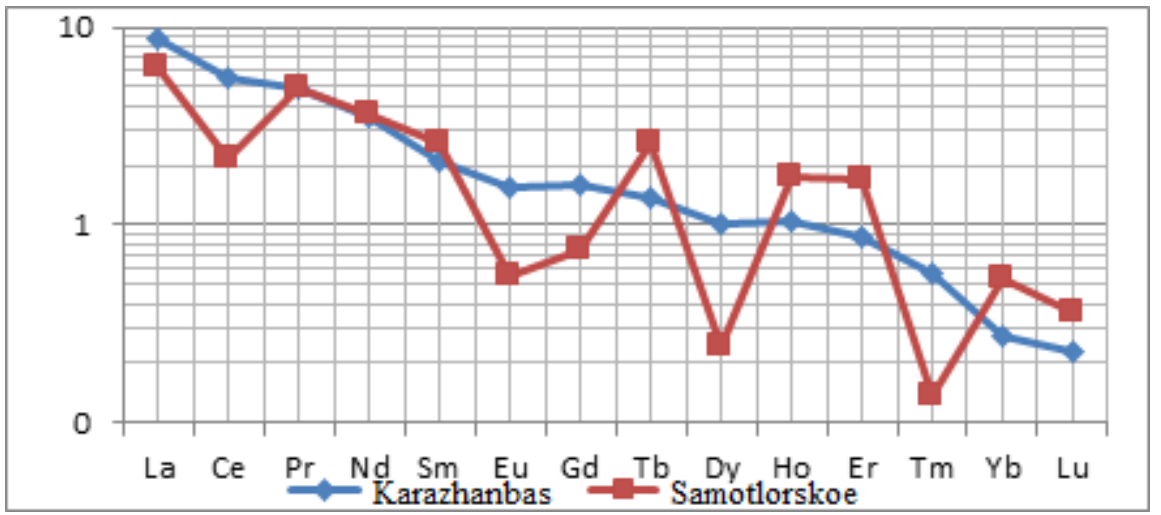




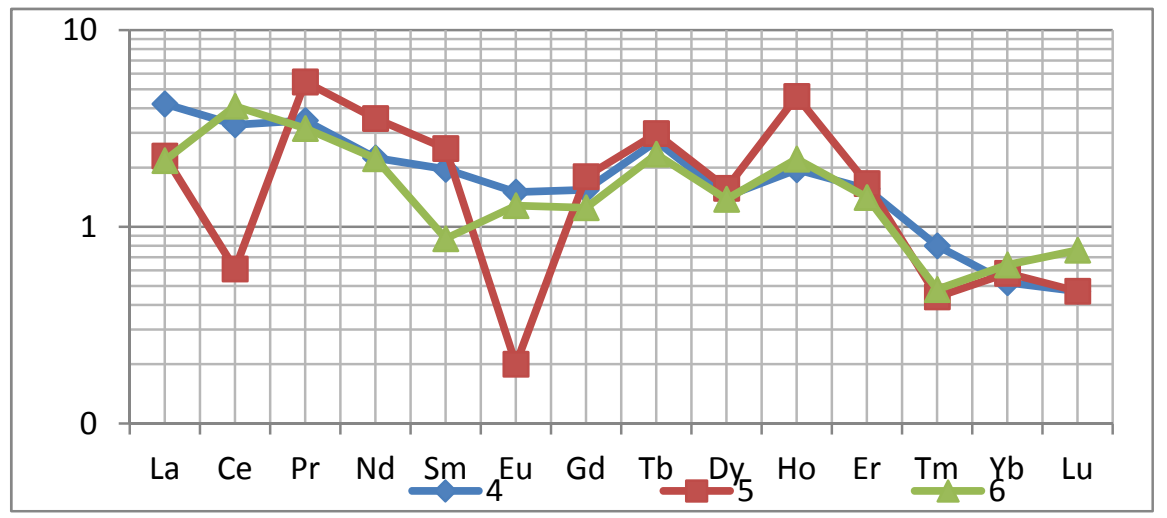

Figure 8. Lanthanide distribution in REE composition of insoluble residue in the oil zone of the Kokdumalak oil and gas-bearing field (Taylor and McLennan, 1988) compared with the lanthanide distribution in the REE composition of asphaltenes of the oil produced from the Samotlor field (Western Siberia).

Figure 8 shows that the lanthanide distribution in the REE composition of asphaltenes of the oil produced from the Samotlor field and the insoluble residue of carbonate reef sediments obtained from the zone of water bearing site (sample 5) from the work (Tsoy, 2013), are almost identical, which is rarely occurred within the natural conditions, and states on the passage of the same physic-chemical processes in the zone of movable mineral and organic complexes contact. Hence, it is easy to trace the unified mechanism of isomorphism manifestations, in light of the recent data on the REE ionic radii in eightfold coordination (Shannon, 1976), terbium $\left(\mathrm{Tb}^{4+}=0.88 \AA\right.$ ) and neodymium $\left(\mathrm{Nd}^{3+}=1.109 \AA\right)$ with replacement of magnesium $\left(\mathrm{Mg}^{2+}=0.89 \AA\right)$ and calcium $\left(\mathrm{Ca}^{2+}=1.12 \AA\right)$, respectively, in the oil and gas-bearing deposits with the difference in the ionic radii of elements $-0.01 \AA$ in the replacement reactions. The sequence of such a mechanism we can see in the following:

$$
\text { Petroleum fluids }+\mathrm{Ca}, \mathrm{MgO}+2 \mathrm{CO}_{2}=\mathrm{Ca}, \mathrm{MgCO}_{3}+2 \mathrm{CO}_{2}+2 \mathrm{H}_{2} \mathrm{O}=\mathrm{Ca}^{2+}, \mathrm{Mg}^{2+}+4 \mathrm{HCO}_{3} \text { (Tsoy, 2013) }
$$

With the arrival of petroleum fluids into the reservoir or with their formation during the catagenetic transformations of organic matter buried in the sediments, there may occur a solvation by organic acids of the oil and gas hydrocarbons, followed by precipitation of carboxylic and naphthenic acids in the form of insoluble calcium $\left(\mathrm{Ca}^{2+}\right)$ and magnesium $\left(\mathrm{Mg}^{2+}\right)$ salts (Tisso and Welte, 1981). After replacing the latter with neodymium $\left(\mathrm{Nd}^{3+}\right)$ and terbium $\left(\mathrm{Tb}^{4+}\right)$ in the contact zone of mineral and organic rock parts, as a final stage of the interaction, there occurs the formation of complex lanthanide compounds with an organic matter in compliance with the scheme of ion exchange of anions (oil and gas hydrocarbons) and cations (REE), as a result of which we observe the concentration of lanthanides in the oil and gas hydrocarbons and their high molecular weight compounds (Tsoy, 2013).

REE in the HMWC fractions of the residual oil. In general, the nature of the lanthanide distribution in the REE composition (Figure 9) is not very different from the lanthanide distribution in the produced oil (Figure 7). Geochemical behavior of lanthanides is based on the same physical and chemical processes taking place in the sediments with the presence of oil and gas hydrocarbons. There can be noted only the degree of influence and participation of the pumped stratum water and SAS in the "Urshak" field with respect to the Samotlor field. It is also possible to assume about the later development of the "Urshak" field and less impact on the site of the injected water reservoir and surface active substances on a uniform distribution of lanthanides in the REE composition of lubricants with respect to the resins and asphaltenes, and lubricants of the Samotlorskoe field. On the lanthanide distribution in asphaltenes, we can judge about the deep destruction of the oil and gas hydrocarbons and a significant impact on the injected water reservoir, resulting in an oxidizing environment and lanthanide isomorphism. 


\section{Lubricants}

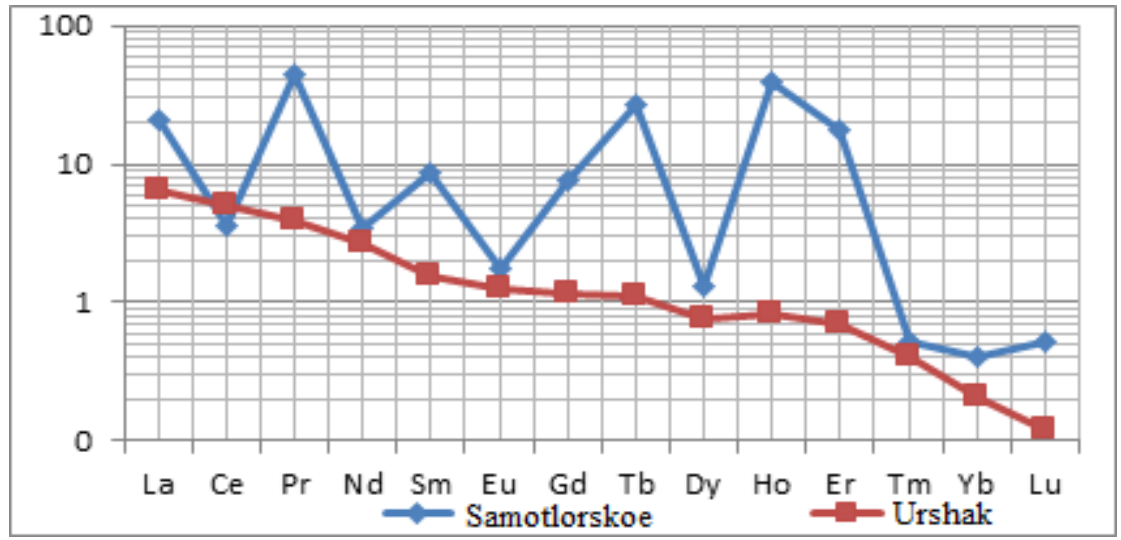

Resins

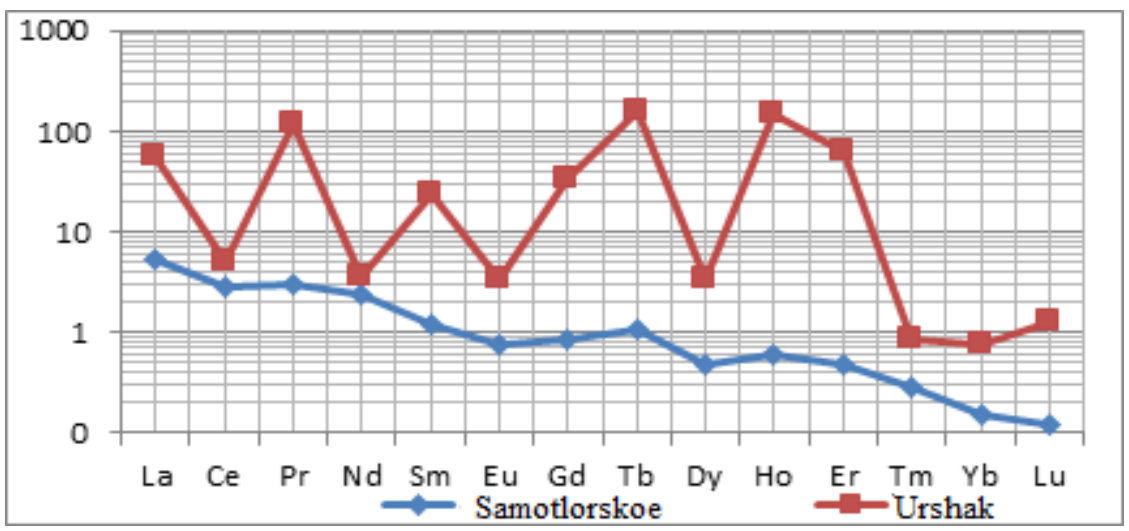

Asphaltenes

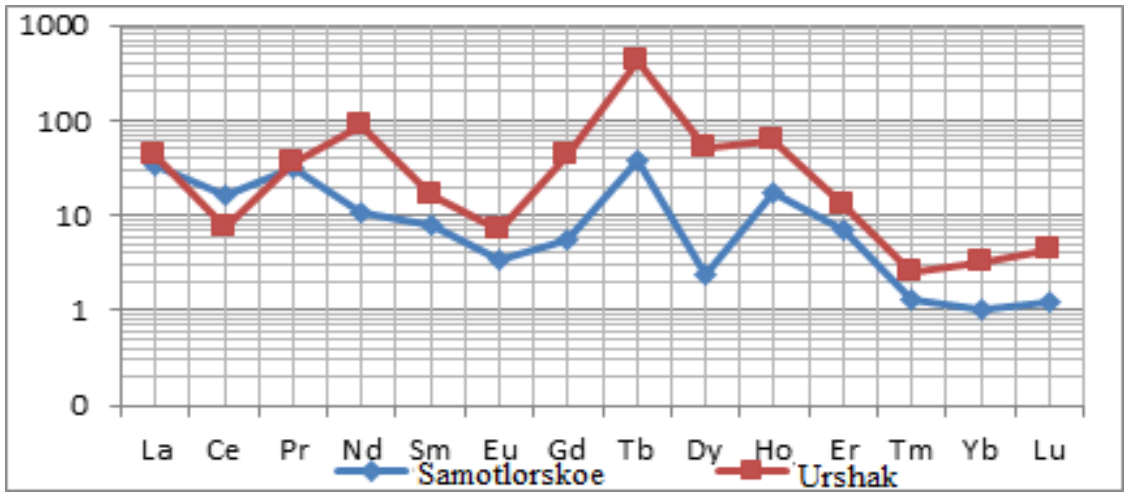

Figure 9. Contrast in the lanthanide distribution in the REE composition and their variations in the HMWC of oils (residual oil)

\section{Conclusion}

Preliminary analysis of the oils' HMWC of various fields shows that the results of studies can be used in the exploitation of oil and gas-bearing fields as a method of controlling the development of the deposit areas, directly on the analysis of oils, and subsequently, if necessary on the HMWC - lubricants, resins and asphaltenes. Hence, there forms the ability to create deposit's technological data sheets on the basis of analysis of initial REE distribution in the oil with reference to the start well debit, and further changes in the REE behavior in subsequent cycles of production, up to the end of exploitation of a particular deposit site. The proposal concerning the possibility of using the geochemical behavior of rare earth elements on their analysis in the produced oils is related to the current absence of any similar effective methods of controlling the development of oil and gas fields. In turn, the identified lanthanide anomalies in the oil's HMWC prior and during the field exploitation, allows to control the changes of redox conditions on the lanthanide distribution in the REE 
composition, thus, in perspective, to establish correlations in time with the technological process of oil and gas production.

From the analysis of lanthanide distributions in the oil's HMWC, it fallows that one of the reasons for the accumulation of terbium in the organic part of the rocks is its presence in the form of $\mathrm{Tb}^{4+}$ as a result of oxidation and (or) isomorphism, and stability in such a form is provided to it by the oil and gas hydrocarbons themselves (no other factors) (Tsoy, 2013). This version is clearly visible in the form of positive terbium fluctuations as exemplified by the lanthanide distribution in REE composition of extracts of the alcohol-benzene mixture (Figure 4). Consequently, by the behavior of terbium $\left(\mathrm{Tb}^{4+}\right)$ we can further judge on the degree of the redox environment. It is impossible not to note the fluctuations of ytterbium $(\mathrm{Yb})$ and lutetium $(\mathrm{Lu})$ with terbium and holmium. Their positive fluctuations in the REE composition of HMWC do not contradict with the REE properties of increasing complexing properties of lanthanides with decreasing their ionic radii in the row of $\mathrm{La}-$ $\mathrm{Lu}$, but they do not carry the required informative value within the subject of the matter under discussion. So, there are two reasons for the abnormal accumulation of terbium in the REE composition - oxidation and isomorphism. The first is controlled by the presence of positive anomalies in the lanthanide spectrum in the REE composition of praseodymium $(\mathrm{Pr})$ with the absence of neodymium $(\mathrm{Nd})$, which is reflected in the Figure 8,9 in the spectra of lubricants and resins. In turn, heterovalent isomorphism of terbium is impossible to be observed without the presence of $(\mathrm{Nd}, \mathrm{Tb}$, and $\mathrm{Pr})$ in the lanthanide spectrum in the REE composition of asphaltenes (Figure 8, 9), especially, $(\mathrm{Nd})$ as the latter together with terbium are always the products of replacement of calcium $\left(\mathrm{Ca}^{2+}\right)$ and magnesium $\left(\mathrm{Mg}^{2+}\right)$ in the hydrogen carbonates of the oil and gas-bearing deposits (Tsoy, 2013, Tisso and Welte, 1981). Hereof follows an important conclusion for the REE geochemistry - increase of isomorphic capacity in relation to REE in the oil and gas-bearing deposits occurs due to solvation of oil and gas hydrocarbons by organic acids, as a consequence of the deposition of the latter in the form of insoluble calcium and magnesium salts (Tisso and Welte, 1981). Anomalies on Holmium (Ho) we relate to the isovalent isomorphism and replacement of yttrium (Y), which was discussed earlier in the analysis of carbonate sediments in the reef (Tsoy, 2013). In terrigenous sediments, the cause of such "paradox" observation is expected due to the presence during the oil and gas deposit development of both, the restoring and oxidizing conditions in the reservoir on some isolated sites related to the phased development of the field and changes of the thermodynamic conditions and transformation of oil into the reservoir. It is worth mentioning that the discussed in the works of Evans, Roger and Bailey et al. (Bailey et al, 1974; Evans et al, 1971; Rogers et al, 1972; Deroo et al, 1974) geochemical conditions for the observation of changes were made and considered probably to the development of the field, and these are quite different conditions of interaction of oil and gas hydrocarbons with rare earth elements.

\section{Summary}

1. The most important conclusion is the thesis about the possibility of observing the geochemical conditions within the reservoir according to the changes of lanthanide concentration of HMWC in time, which will allow for the further coordination of the obtained results, taking into account the geochemical behavior of REE, especially on the distribution in lubricants and resins, after the volume of the injected water, surface active substances and access to petroleum fluids.

2. Another important research result in the behavior of REE is the establishment of the individual lanthanide isomorphism found in the oil's asphaltenes, which has not been observed earlier and is presented in this work for the first time. Establishing of the naphthides influence factor as a fundamental on the isomorphism of individual lanthanides is in the geochemistry of rare earth elements of sedimentary processes an unusual fact and becomes an evidence base on the possibility of terbium $(\mathrm{Tb})$ accumulation in petroleum fluids in the form of $\mathrm{Tb}^{4+}$.

\section{Acknowledgements}

The author is grateful for the tremendous work made on the extraction of high molecular weight compounds from oil to Gerasimov, N.N. (Institute of Petroleum Chemistry SB RAS, Tomsk); Tishchenko, V.M., Deputy Director of the Tomsk Branch of the Siberian Scientific and Research Institute of Geology, Geophysics and Mineral Resources for the discussion of the problem of geochemical controlling the exploitation of oil and gas-bearing deposits; Balashov, Y.A., Doctor of Geological Mineralogical Sciences, Professor of the Geological Institute of the Kola Scientific Center of the Russian Academy of Sciences (Apatity, Murmansk region) for advising and discussing the article.

\section{References}

Bailey, N. J. L., Evans, C. R., \& Milner, C. W. (1974). Applying petroleum geochemistry to search for oil, examples from western Canada Basin. Am. Assoc. Pet. Geol. Bull., 58, 2284-2294. 
Balashov, Y. A., \& Tsoy, K. S. (1989). The role of redox conditions in the $\mathrm{Eu}^{2+}, \mathrm{Yb}^{2+}$ and $\mathrm{Sm}^{2+}$ accumulation in oils. DAN, 5(389), 1189-1192.

Balashov, Y. A. et al. (1964). The effect of climate and facies environment on the fractionation of the rare earths during sedimentation. Geochem. Int, 10, 951.

Balashov, Y. A. (1976). Geochemistry of rare earth elements. M.: Science, pp: 276.

Deroo, G., B. Tissot, R. G. McGrossan \& Der, F. (1974). Geochemistry of the heavy oils of Alberta, In Oil Sands Fuel of the Future. Memoir 3. Can. Soc. Pet. Geol.: 148-167, 184-189.

Dubinin, A. V. (2006). Geochemistry of rare earth elements in the ocean. M.: Science, pp: 24-26.

Evans, C. R., Rogers, M. A., \& Bailey, N. J. L. (1971). Evolution and alteration of petroleum in Western Canada. Chem. Geol., 8, 147-170. http://dx.doi.org/10.1016/0009-2541(71)90002-7

Gottikh, R. P., Pisotsky, B. I., Spiridonov, D. N., \& Krivosheya, V. A. (1990). Metallogenic feature of liquid and carbonaceous substances in the sediments of the Dnieper-Donets Basin. DAN SSSR, 6(312), 1445-1450.

Gottikh, R. P., Vinokurov, S. F., \& Pisotsky, B. I. (2009). Rare earth elements as geochemical criteria of endogenous sources of trace elements in oil. DAN RAS, 2(425), 1-3.

Gromet, L. P., Dymek, R. F., Haskin, L. A., \& Korotev, R. L. (1984). The North American shale composite: Its compilation, major and trace element characteristics. Geochem. et cosmochem. acta, 12(48), 2469-2482. http://dx.doi.org/10.1016/0016-7037(84)90298-9

Gurari, F. G., Gavshin, V. M., Matvienko, N. I., Pereladov, V. S., Bobrov, V. A., Smertina, L. N., \& Shestel, S. T. (1984). Geochemistry of trace elements in marine planktonogenic sediments of the Lower-Middle Cambrian of the Siberian Platform. Coll. Rep. "Association of trace elements with organic substance in sedimentary strata of Siberia". Novosibirsk: IGiG SB AS USSR, pp: 41-69.

Haskin, L. A. et al. (1966). Rare earth in sediments. JGR, 71, 6091. http://dx.doi.org/10.1029/JZ071i024p06091

McDonough, W. F., \& Sun, S. S. (1995). The Composition of the Earth. Chemical Geology, 120, 223-253. http://dx.doi.org/10.1016/0009-2541(94)00140-4

Migdisov, A. A., Balashov, Y. A., \& Sharkov, I. V., et al. (1994). Prevalence of the rare earth elements in the main lithological types of rocks of the Russian Platform sedimentary cover. Geochemistry, 6, 789-803.

Rogers, M. A., Bailey, N. J. I., Evans, S. R., \& McAlary, J. D. (1972). Au Explanatory and Predictive Model for the Alteration of Crude Oils in Reservoirs in the Western Canada Basin. Proc. Int. Geol. Congr., Montreal, Canada. Mineral Fuels Sec., 5, 48-55.

Ronov, A. B., Balashov, Y. A., \& Migdisov, A. A. (1968). The main features of the geochemistry of rare earth elements in the sedimentary cycle. Coll. Rep. "The physical and chemical processes and facies". M.: Science, pp: 80-85.

Shannon, R. D. (1976). Revised effective ionic radii and systematic studies of interatomic distances in halides and chalcogenides. Acta Crystallogr., F32: 751-767.

Taylor, S. R., \& McLennan, S. M. (1988). The continental crust: its composition and evolution. M.: Mir, pp: 47-75.

Tisso, B., \&Welte, D. (1981). Oil formation and dissemination. M.: Mir, pp: 260-263.

Tsoy, K. S. (2013). Rare earth elements and Yttrium in carbonate reef deposits containing hydrocarbons of oil and gas. World Applied Science Journal, 24(2), 256-266. ISSN 1818-4952.

Zanin, Y. N., Zamirailova, A. G., Eder, V. G., \& Krasavchikov, V. O. (2011). Rare earth elements in the Bazhenov Formation of the West Siberian sedimentary basin. Lithosphere, 6, 38-54.

\section{Copyrights}

Copyright for this article is retained by the author(s), with first publication rights granted to the journal.

This is an open-access article distributed under the terms and conditions of the Creative Commons Attribution license (http://creativecommons.org/licenses/by/3.0/). 